\title{
Topical aural antibiotic use in the UK - time for a change of policy?
}

Practitioners in the UK can be excused for being confused when it comes to the appropriate use of topical antibiotics for discharging ears. The two groups of antibiotics used topically in the ear are aminoglycosides and quinolones. Confusion over their use arises from two points of contention. Firstly, is the fact that because of potential ototoxicity the data sheets for topical aminoglycosides advise against their use in the presence of a non-intact tympanic membrane. Secondly, quinolones are not licensed for aural topical use in the UK. These issues are discussed in detail in a review article by Harris and colleagues. ${ }^{1}$ The authors review the effectiveness of topical quinolones in chronic suppurative otitis media, and conclude that they are equal or more effective in treating chronic suppurative otitis media than aminoglycosides. The potential development of antibiotic resistance to quinolones is cited as a theoretical disadvantage in their use, although in practice there does not appear to be any evidence for this. It seems that, possibly as a result of the licensing anomaly, the ENT-UK guidelines concerning the use of topical antibiotics ${ }^{2}$ are out of step with those currently in place in the USA, Canada, Australia and New Zealand.

Otolaryngologists the world over will be familiar with their patients having a high level of psychiatric morbidity. Otological complaints are particularly likely to be associated with depression and anxiety, with tinnitus being perhaps the most frequently associated symptom. ${ }^{3}$ Two articles in this issue address this association. Yilmaz and colleagues examined patients with isolated itching of the external auditory canal and found a very high level of type $\mathrm{D}$ personality, characterised by depression, negative affect and social inhibition. ${ }^{4}$ The occurrence of depressive disorders in patients with sudden sensorineural hearing loss is perhaps more of a surprise. ${ }^{5}$ Lin and colleagues, however, in a large population-based study, found a 1.45 times higher level of sudden sensorineural hearing loss in patients with depression compared to those without. ${ }^{6}$ Co-morbidities such as diabetes mellitus, chronic renal disease and hyperlipidaemia also significantly increased the risk of sudden hearing loss.

Early diagnosis of head and neck cancer is accepted to be the principle behind good patient outcomes and survival in these conditions. In the UK, the process of referral for suspected cancer is acknowledged to have scope for improvement. ${ }^{7}$ Gogarty and colleagues investigate the possibility of designing a national head and neck cancer screening programme. ${ }^{8}$ They recommend tailored screening programmes for specific populations known to be at risk of developing head and neck cancer, rather than mass population screening.

Finally, the Editors and staff of The Journal of Laryngology \& Otology welcome readers to this new 2016 volume. To the Senior Editorial staff, we welcome Musheer Hussain and Jonathan Fishman. It is also with sadness that we mention the passing away of Sue Perkins. Sue was our main journal production contact at Cambridge University Press; she worked closely with The Journal staff to ensure the timely and effective publication of The Journal. She will be very much missed by all who had the privilege of working with her.

\section{ROBIN YOUNGS EDWARD FISHER MUSHEER HUSSAIN JONATHAN FISHMAN Senior Editors}

\section{References}

1 Harris AS, Elhassan HA, Flook EP. Why are ototopical aminoglycosides still first-line therapy for chronic suppurative otitis media? A systematic review and discussion of aminoglycosides versus quinolones. J Laryngol Otol 2016;130:2-7

2 Philips JS, Yung MW, Burton MJ, Swan IR. Evidence review and ENT-UK consensus report for the use of aminoglycoside-containing ear drops in the presence of an open middle ear. Clin Otolaryngol 2007;32:330-6

3 Pinto PC, Marcelos CM, Mezzasalma MA, Osterne FJ, de Melo Tavares de Lima MA, Nardi AE. Tinnitus and its association with psychiatric disorders: systematic review. J Laryngol Otol 2014; 128:660-4

4 Yilmaz B, Canan F, Șengül E, Özkurt FE, Tuna SF, Yildirim H. Type D personality, anxiety, depression and personality traits in patients with isolated itching of the external auditory canal. J Laryngol Otol 2016;130:50-5

5 Sara SA, Teh BM, Friedland P. Bilateral sudden sensorineural hearing loss: review. J Laryngol Otol 2014;128(suppl 1):S8-15

6 Lin CS, Lin YS, Liu CF, Weng SF, Lin C, Lin BS. Increased risk of sudden sensorineural hearing loss in patients with depressive disorders: population-based cohort study. J Laryngol Otol 2016;130:42-9

7 Bethell GS, Leftwick P. Views of general practitioners and head and neck surgeons on the referral system for suspected cancer: a survey. J Laryngol Otol 2015;129:893-7

8 Gogarty DS, Shuman A, O'Sullivan EM, Sheahan P, Kinsella J, Timon $\mathrm{C}$ et al. Conceiving a national head and neck cancer screening programme. J Laryngol Otol 2016;130:8-14 